\title{
Bladder sensory desensitization decreases urinary urgency Carlos Silva1 ${ }^{1}$ João Silva ${ }^{1}$, Helder Castro ${ }^{1}$, Frederico Reis ${ }^{1}$, Paulo Dinis ${ }^{1}$, António Avelino ${ }^{2}$ and Francisco Cruz ${ }^{* 1,2}$
}

\author{
Address: ${ }^{1}$ Department of Urology, Hospital S. João and Faculty of Medicine of Porto, Porto, Portugal and ${ }^{2}$ Department of Histology and \\ Embryology, Faculty of Medicine of Porto and IBMC of the University of Porto, Porto, Portugal \\ Email: Carlos Silva - carsil@med.up.pt; João Silva - jfalturas@yahoo.com; Helder Castro - hfncastro@gmail.com; \\ Frederico Reis - fcreis@runbox.com; Paulo Dinis - paulodinisoliveira@gmail.com; António Avelino - aavelino@med.up.pt; \\ Francisco Cruz* - cruzfjmr@med.up.pt \\ * Corresponding author
}

Published: II June 2007

BMC Urology 2007, 7:9 doi:10.1 186/1471-2490-7-9

This article is available from: http://www.biomedcentral.com/I47I-2490/7/9

(C) 2007 Silva et al; licensee BioMed Central Ltd.

This is an Open Access article distributed under the terms of the Creative Commons Attribution License (http://creativecommons.org/licenses/by/2.0), which permits unrestricted use, distribution, and reproduction in any medium, provided the original work is properly cited.

\begin{abstract}
Background: Bladder desensitization has been investigated as an alternative treatment for refractory detrusor overactivity. Most open and controlled clinical trials conducted with intravesical RTX showed that desensitization delays the appearance of involuntary detrusor contractions during bladder filling and decreases the number of episodes of urgency incontinence.
\end{abstract}

Urgency is being recognised as the fundamental symptom of overactive bladder (OAB), a symptomatic complex which recent epidemiological studies have shown to affect more than $10 \%$ of the Western population. As antimuscarinic drugs, the first line treatment for $O A B$, are far from being able to fully control urgency, the opportunity to test other therapeutic approaches is created. The present work was, therefore, designed as an exploratory investigation to evaluate the effect of bladder desensitization on urinary urgency.

Methods: Twenty-three $O A B$ patients with refractory urgency entered, after given informed consent, a 30 days run-in period in which medications influencing the bladder function were interrupted. At the end of this period patients filled a seven-day voiding chart where they scored, using a $0-4$ scale, the bladder sensations felt before each voiding. Then, patients were instilled with $100 \mathrm{ml}$ of $10 \%$ ethanol in saline (vehicle solution) and 30 days later a second seven-day voiding chart was collected. Finally, patients were instilled with $100 \mathrm{ml}$ of $50 \mathrm{nM} \mathrm{RTX} \mathrm{in} 10 \%$ ethanol in saline. At I and 3 months additional voiding charts were collected.

At the end of the vehicle and 3 months period patients were asked to give their subjective impression about the outcome of the treatment and about the willingness to repeat the previous instillation.

Results: At the end of the run-in period the mean number of episodes of urgency per week was $71 \pm 12$ (mean \pm SEM). After vehicle instillation, the mean number of episodes of urgency was $56 \pm \mathrm{II}$, but only 4 patients (I7\%) considered that their urinary condition had improved enough to repeat the treatment. At I and 3 months after RTX the number of episodes of urgency decreased to $39 \pm 9(p=0.002)$ and $37 \pm 6(p=0.02)$, respectively ( indicates statistical differences against vehicle). The percentage of patients with subjective improvement after RTX and willing to repeat the instillation at a later occasion was $69 \%$.

Conclusion: In $O A B$ patients with refractory urgency bladder desensitization should be further investigated as an alternative to the standard management. Additionally, the specific effect of RTX on TRPVI receptors suggests that urothelium and sub-urothelial C-fibers play an important role to the generation of urgency sensation. 


\section{Background}

Resiniferatoxin (RTX), the ultrapotent capsaicin analogue, was shown to desensitize TRPV1, a non-specific calcium channel, which is abundantly expressed in neuronal and non-neuronal bladder structures, including type C-sensory fibers [1], urothelial cells [2,3] and possibly interstitial cells [4]. Following desensitization, TRPV1 becomes less responsive to further activation by RTX or similar compounds and its expression is strongly reduced, both in the urothelium [3] and in sensory nerve fibers [5]. In addition, experimental studies have shown that desensitization reduces bladder response to distension, as shown by the increase of the volume threshold to reflex voiding [6] and decreased activation of sensory driven spinal cord genes as c-fos [7].

Urgency is being recognised as the fundamental symptom of overactive bladder (OAB), a symptomatic complex which recent epidemiological studies have shown to affect more than $10 \%$ of the Western population [8]. Unfortunately, anti-muscarinic drugs, the first line treatment for $\mathrm{OAB}$, although providing some improvement, are far from being able to fully control this bothersome lower urinary tract symptom [9]. This creates the opportunity to test other therapies that, if promising, can be offered as second line options.

Bladder desensitization has been exploited in the last decade as an alternative treatment for refractory detrusor overactivity [10,11]. Most open [12-15] and controlled [16-18] clinical trials conducted so far showed that the number of episodes of urgency incontinence in patients with detrusor overactivity was decreased by intravesical RTX at the same time at which the compound delayed the appearance of involuntary detrusor contractions during bladder filling and increased bladder capacity. Furthermore, in a controlled study, the global urinary condition improved in $62 \%$ of detrusor overactivity (DO) patients treated with intravesical RTX but only in $21 \%$ of those that received the vehicle solution alone [18]. The effect of RTX on urgency was also reported in $\mathrm{OAB}$ patients without DO. In a small open label study RTX showed a trend to decrease the number of episodes of urinary urgency [19].

The present work was designed to further explore the effect of bladder desensitization on urinary urgency. As a primary objective it was investigated if intravesical RTX could reduce the number of episodes of urinary urgency. As a secondary objective the effect of bladder desensitization on urgency incontinence and urinary frequency was also analysed. This study was presented in part in abstract form [20].

\section{Methods}

Twenty-three patients ( 7 males and 16 females with a mean age of 50 years, range 21-77) with $\mathrm{OAB}$ refractory to antimuscarinics were enrolled during 2005. All patients had at least 7 urgency episodes per week. Six patients had a neurogenic cause for $\mathrm{OAB}$ symptoms whereas the remaining patients were idiopathic. All gave written informed consent approved by the Ethics Committee of our Institution to receive intravesical RTX. The following exclusion criteria to enter the study were observed: age less than 18 years, pregnancy, known cardiovascular, renal, hepatic or psychiatric disorders, malignant diseases, duration of the OAB syndrome less than 12 months and concomitant bladder diseases, namely lower urinary tract symptoms suggestive of bladder outlet obstruction and/or treatments influencing bladder performance. In addition, patients were excluded in the presence of abnormal haematological and biochemical blood tests, abnormal kidney and bladder ultrasound and a positive urine culture.

The design of the study was the following. At the first visit the patients were enrolled in the study and entered a runin period of 30 days during which anti-muscarinic drugs or other drugs that could affect bladder function were stopped. Patients filled a voiding chart of the last 7 days of this period. At the second visit the voiding chart was collected and patients were instilled during 30 minutes with $100 \mathrm{ml}$ of the vehicle used to prepare the RTX solution, $10 \%$ ethanol in saline. The patients were then sent home for another 30 days. In the last seven days of this period patients filled another voiding chart. At the third visit the voiding chart corresponding to the vehicle period was collected and $100 \mathrm{ml}$ of a $50 \mathrm{nM}$ RTX solution were slowly instilled into the bladder by gravity and left in contact with the mucosa during 30 minutes. If detrusor contractions occurred, the solution could freely reflux into the container and then return into the bladder once the contractions wanned. The patients were sent home at the end of the treatment. Two additional visits were scheduled at 1 and 3 months after RTX instillation. At the end of each period, 7 day voiding charts were collected. At the end of the vehicle and 3 months period patients were asked to give their subjective impression about the outcome of the treatment and about the willingness to repeat the previous instillation. During the duration of the study no urodynamic studies were performed as the definitions of urgency and $\mathrm{OAB}$ are purely clinic.

A validated scale to assess urinary urgency is not yet available in the Portuguese language. In addition, the distinction between the words urge and urgency, possible in the English language, has no equivalent in Portuguese. Therefore, the suggestion for describing urgency according to the circumstances during which it was experienced and by the impact it had on concomitant activity being carried by 
the patients was followed to build up a scale easily understandable by the patients [21]. The options are listed below and the system score was taught to the patients at the first visit. Only options 3 and 4 were considered as equivalents of urgency. Option 2 was used to refer urge.

0 - "I voided because it was convenient although I did not feel a bladder sensation".

1 - "I voided because I had the sensation that my bladder was becoming full and the opportunity to void was convenient".

2 - "I voided because I had the sensation that my bladder was extremely full. I looked for a convenient place to void without feeling any eminent risk of urine leakage".

3 - "I voided because I had a sudden strong desire to void which I felt that could cause an urine leakage. I immediately interrupted what I was doing and looked for a convenient place where I started voiding in time".

4 - "I had a sudden strong desire to void that I felt that could cause urine leakage. Although I immediately looked for a convenient place to void, I had a leak before starting voiding".

RTX was obtained from Sigma and a $10 \mathrm{mM}$ stock solution in pure ethanol was prepared and kept in the dark at $4{ }^{\circ} \mathrm{C}$ in a glass container. For each instillation $100 \mathrm{ml}$ of a $50 \mathrm{nM}$ solution using $10 \%$ ethanol in saline as vehicle was prepared by one of the authors by adding $0.5 \mathrm{ml}$ of the stock solution to $90 \mathrm{ml}$ of saline and $9.5 \mathrm{ml}$ of pure ethanol. Instillation was carried out within 30-60 minutes after preparation to minimise RTX absorption by plastic devices. Instillations of the vehicle solution and of the RTX solution were carried on without any form of analgesia or bladder anesthesia. Oral ciprofloxacin was administered for urinary infection prophylaxis at each instillation.

Urgency events, which corresponded to micturitions scored as 3 or 4 , were counted for each patient at the end of the run-in period, vehicle period and at 1 and 3 months after RTX instillation. The number of patients in whom the number of urgency episodes decreased $25 \%$ or more after vehicle instillation and RTX was counted. Patients who considered to have had a subjective improvement at the same time points and would repeat instillations if necessary at a later occasion were also counted. The number of micturitions per week was obtained from the micturition charts. Data are presented as mean values per week \pm standard error of the mean (SEM). Those at the vehicle period and at 1 and 3 months after RTX instillation were compared by a two-tailed paired t-test for means. Percentage of patients with $\geq 25 \%$ improvement in urgency epi- sodes and with subjective improvement after vehicle and RTX treatment was compared by a z-test. A p $<0.05$ was considered statistically significant.

\section{Results}

At the end of the run-in period the mean number of episodes of urgency per week, that is micturition events preceded by sensations scored as 3 or 4 , was $71 \pm 12$. The average number of episodes of urgency after vehicle instillation was $56 \pm 11$. Nine patients (39\%) had a decrease in the number of episodes of urgency equal or superior to $25 \%$. However, only 4 patients $(17 \%)$ considered that their urinary condition had improved enough to repeat the treatment. The average number of urgency episodes at 1 and 3 months after RTX instillation was $39 \pm 9(\mathrm{p}=$ 0.002 against vehicle) and $37 \pm 6(\mathrm{p}=0.02$ against vehicle), respectively (Fig. 1). After RTX a $25 \%$ or more decrease over the number of episodes of urgency counted at the end of the vehicle period occurred in 14 patients representing an increase in the percentage of RTX responders to $60 \%$. However this variation should be taken as a trend since it did not achieve statistical significance ( $\mathrm{p}=0.2)$. The percentage of patients with subjective improvement after RTX and willing to repeat the instillation at a later occasion increased to $69 \%$. $(\mathrm{p}=0.001$, Fig. 2).

The episodes of urgency associated with incontinence were evaluated separately. At baseline the mean number was $21 \pm 5$. They decreased to $12 \pm 4$ after placebo instillation. At 1 and 3 months after RTX the episodes of urgency incontinence further decreased to $8 \pm 3$ and $9 \pm 3$, respectively. However, these values were not statistically different from those after vehicle instillation $(\mathrm{p}=0.05$ and $\mathrm{p}=0.1$, respectively).

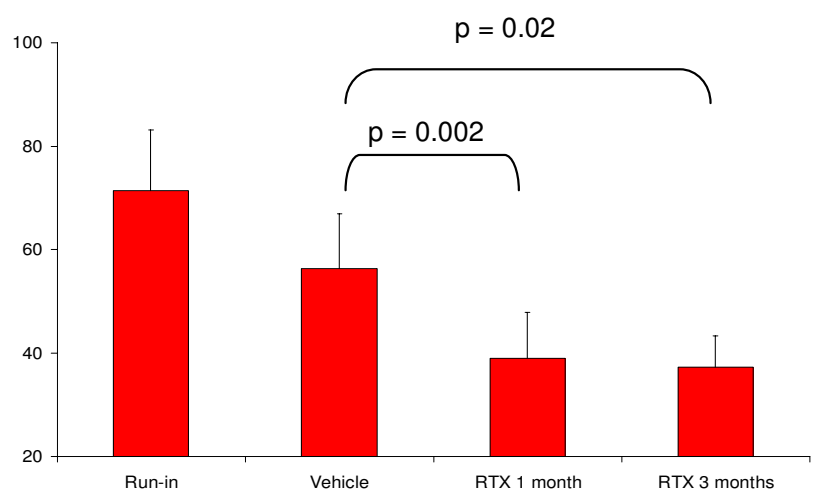

Figure I

Number of episodes of urgency at the run-in period, after the instillation of the vehicle solution and at $I$ and 3 months after 50 nM RTX instillation. 


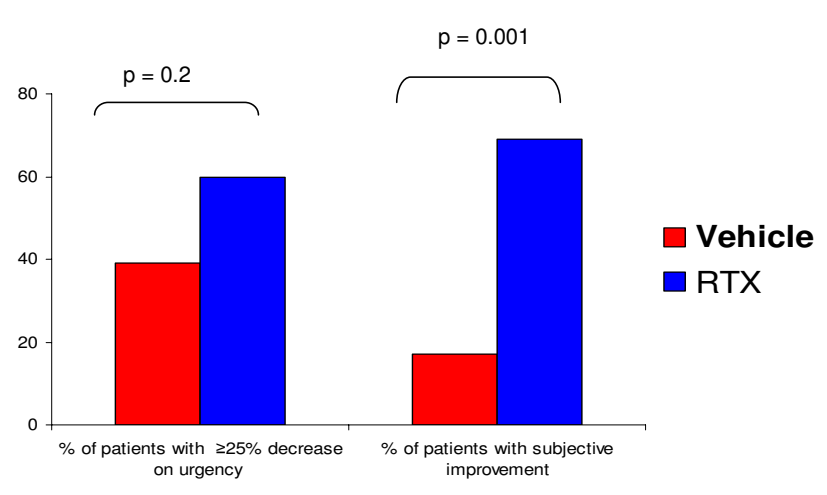

Figure 2

Percentage of patients with a $25 \%$ or more decrease on the number of episodes of urgency per week and percentage of patients with subjective improvement and willing to repeat the instillation if necessary, after vehicle (red bars) or $50 \mathrm{nM}$ RTX instillation (blue bars).

The number of micturitions per week, which was $95 \pm 11$ at the run-in period, decreased to $87 \pm 10$ after the vehicle instillation. A further decrease to $75 \pm 8$ at 1 month ( $\mathrm{p}=$ 0.02 against vehicle) and to $75 \pm 7$ at 3 months ( $p=0.03$ against vehicle) was observed after the RTX instillation (Fig 3).

RTX instillation was associated with a slight discomfort, described by patients as an itch sensation or urgency to urinate. In no case was analgesic medication required or instillation interrupted. After RTX treatment none of the patients reported difficulties in emptying the bladder.

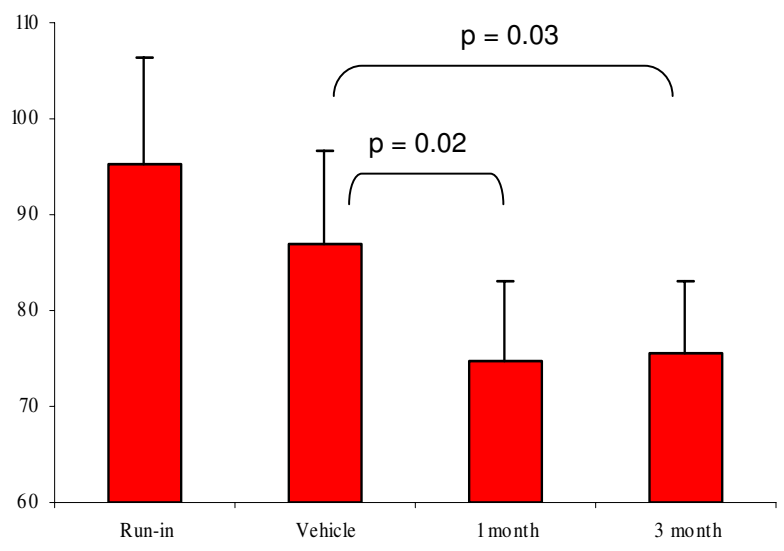

Figure 3

Number of micturition episodes per week at the run-in period, after the instillation of the vehicle solution and at I and 3 months after $50 \mathrm{nM}$ RTX instillation.

\section{Discussion}

The most important finding of the present study was the decrease of the number of episodes of urinary urgency induced by bladder desensitization. Urinary frequency also decreased and urgency incontinence showed a strong trend to a reduction. These objective changes were accompanied by a subjective improvement in more than two thirds of the patients. In addition, this study further confirmed the reports of good tolerability of RTX instillation in low concentrations $[13,16]$. In spite of the fact that no bladder anaesthesia was performed, all our patients carried out the 30 minutes RTX instillation to the end without difficulty.

This study was exploratory and was not designed as a randomized double arm placebo controlled trial due to the limitations in recruiting patients for an off-license treatment in one single center. Nevertheless mean episodes of urgency and micturition occurring 1 and 3 months after RTX instillation were significantly less than those after the simple instillation of the vehicle solution. In addition, RTX brought a $25 \%$ improvement in the number of episodes of urgency over the vehicle period to $60 \%$ of the patients whereas vehicle application alone had caused a similar improvement rate over the run-in period in only $39 \%$ of the patients.

Due to the lack of validated scales to quantify urgency in the Portuguese language we had to build-up a scale to assess this symptom. As the words urge and urgency have no equivalent in the Portuguese language we preferred a scale which evaluated the circumstances in which urgency occurred and its impact on the patients' daily activities, rather than its intensity. Although our option might be object of criticism, actually, the best mean to evaluate and measure urgency is not yet established and is under intense controversy. Researchers exist who prefer scales in which different degrees of urgency intensity are contemplated $[22,23]$. However others only recognise the necessity of distinguishing urgency form urge and consider that urgency, being a sudden and compelling desire to urinate, does not have degree of severity [24].

The reason for the improvement associated with RTX should be explained by its specific affinity to TRPV1 $[25,26]$. This receptor was recently found to be over expressed in the trigone of patients with urgency [27]. In C-fibers RTX binding to TRPV1 causes a massive inflow of calcium and other ions into the fiber, generating action potentials and releasing neuropeptides from peripheral nerve endings $[25,26]$, both events contributing to itch or urgency sensations reported by some patients in the present and in previous studies in which RTX instillation was carried out $[14,16]$. A transient reduction of bladder sensory input conveyed to the central nervous system in $\mathrm{C}$ 
fibers then follows [7]. The interruption of C-fiber influx may thus have contributed to the symptomatic improvement observed after RTX instillation in our patients.

It is probable that part of sensory input conveyed in C fibers is not initiated by a direct stimulation of peripheral nerve endings but results from their activation by neurotransmitters and neurotrophic factors released from the urothelium [28]. RTX binding to TRPV1 present in urothelial cells may, therefore, have contributed to urgency improvement by disrupting the cross-talk between urothelial cells and suburothelial C-fibers. Inflow currents occur in human urothelial cells after TRPV1 activation suggesting that the receptor in the urothelium retains properties similar to those described in sensory neurons [29]. Likewise RTX application is followed by a reduction in urothelial TRPV1 expression [3]. Thus, RTX treatment might have reduced the potential of urothelial cells to release compounds which are known to excite suburothelial sensory fibres [2]. One of these compounds might be nerve growth factor (NGF) [30]. Although it is unclear at the moment if TRPV1 excitation enhances NGF release from urothelium, this neurotrophin was shown to induce bladder overactivity in experimental animals [31] and was found in high amounts in the urine of $\mathrm{OAB}$ patients [32].

It is also possible that RTX has prevented the ATP released from urothelial cells [2] and consequently the activation of sub-urothelial C-fibers expressing P2X3 receptors [15]. It is known that TRPV1 is involved in ATP release from the urothelium in response to stretch stimuli [33]. In addition, animal studies demonstrated that $\mathrm{P} 2 \mathrm{X} 3$ receptors are essential for the generation of bladder contractions and noxious sensations [34]. As a matter of fact, knocking-out P2X3 in mice renders the bladder hypoactive and the animals less reactive to pain [34]. Intravesical RTX decreases both TRPV1 in urothelial cells [3] and the number of suburothelial P2X3 expressing fibers in the human bladder [15].

In our study the instillation of $10 \%$ ethanol in saline alone caused a marked improvement in the number of urgency episodes when compared to the run-in phase. It seems, however, improbable that such effect was due to a desensitizing action of ethanol on TRPV1 receptors. In fact, although ethanol was found to bind TRPV1, it does not cause its desensitization [35]. In addition, in a recent clinical trial with patients with neurogenic detrusor overactivity $10 \%$ ethanol in saline alone did not cause any variation on urodynamic parameters in contrast with the solution containing RTX $50 \mathrm{nM}$ that significantly increased the bladder volume to first involuntary detrusor contraction and maximal cystometric capacity [16]. Similar findings were reported by Kuo et al. In 54 patiens with refractory DO, $21 \%$ of the patients treated with $10 \%$ ethanol improved at 3 months, a number considerably smaller that the $62 \%$ that improved after RTX $10 \mathrm{nM}$, four weekly instillations [18]. Thus, the improvement induced by $10 \%$ ethanol instillation in the present study should be taken as part of a placebo effect, a commonly recognized phenomenon in clinical trials involving $\mathrm{OAB}$ patients [36].

\section{Conclusion}

This exploratory study indicates that desensitization may be useful to treat patients with urinary urgency, particularly if refractory to the standard management. This finding also has important pathophysiological implications as it indicates that C-fiber input plays an important role to the generation of the urgency sensation. Since at present RTX is the only compound with desensitizing effect suitable for human use, a randomised placebo controlled study is justified to further investigate the role of desensitization in the treatment of urgency. The dose for intravesical RTX used in the present work should be considered as indicative in future studies. In fact, all studies in which RTX was used to treat OAB symptoms $[14,18,19]$, including the present one, used RTX concentrations of $50 \mathrm{nM}$ or lower. In addition, urodynamics studies should be included in future studies. Although it was not the case of this study, urodynamics might elucidate if urgency in patients with or without detrusor overactivity have the same origin.

\section{List of abbreviations}

ATP - adenosine triphosphate

DO - detrusor overactivity

NGF - Nerve Growth Factor

$\mathrm{OAB}$ - Overactive bladder

P2X3 - P2X family of ATP-gated ion channels, subtype 3

RTX - Resiniferatoxin

TRPV1 - Transient receptor potential vanilloid subfamily 1

\section{Competing interests}

The author(s) declare that they have no competing interests.

\section{Authors' contributions}

CS designed the study, was involved in clinical assessment of patients, analysed the data and wrote the manuscript.

CS, JS, HC, FR and PD selected, treated and followed the patients.

AA prepared the resiniferatoxin solutions.

FC participated in the design of the study and its coordination, analysed the data and wrote the manuscript. 
All the authors read and approved the manuscript.

\section{Acknowledgements}

We thank Dr. Célia Duarte Cruz for the statistical analysis. This work was funded by the Portuguese government through Fundação Ciência Tecnologia, project POCI/SAU-NEU/55983/2004.

\section{References}

I. Yiangou Y, Facer P, Ford A, Brady C, Wiseman O, Fowler CJ, Anand $P$ : Capsaicin receptor VRI and ATP-gated ion channel P2X3 in human urinary bladder. BJU Int 2001, 87:774-779.

2. Birder LA, Kanai AJ, de Groat WC, Kiss S, Nealen ML, Burke NE, Dineley KE, Watkins S, Reynolds IJ, Caterina MJ: Vanilloid receptor expression suggests a sensory role for urinary bladder epithelial cells. Proc Natl Acad Sci USA 200I, 98: 13396-1340I.

3. Apostolidis A, Brady CM, Yiangou Y, Davis J, Fowler CJ, Anand P Capsaicin receptor TRPV $I$ in urothelium of neurogenic human bladders and effect of intravesical resiniferatoxin. Urology 2005, 65:400-405.

4. Ost D, Roskams T, Van der Aa F, de Ridder D: Topography of the vanilloid receptorin the human bladder: more than just the nerve fibers. J Urol 2002, 168:293-297.

5. Brady CM, Apostolidis A, Harper M, Yiangou Y, Beckett A, Jacques TS, Freeman A, Scaravilli F, Fowler C], Anand P: Parallel changes in bladder suburothelial vanilloid receptor TRPVI (VRI) and pan-neuronal marker PGP9.5 immunoreactivity in patients with neurogenic detrusor overactivity (NDO) following intravesical resiniferatoxin treatment. BJU Int 2004, 93:770-776.

6. Avelino A, Cruz F: Peptide immunoreactivity and ultrastruc ture of rat urinary bladder nerve fibers after topical desensitization by capsaicin or resiniferatoxin. Autonomic Neuroscience: Basic and clinical 2000, 86(I-2):37-46.

7. Avelino A, Cruz F, Coimbra A: Intravesical resiniferatoxin desensitizes rat bladder sensory fibers without causing intense noxious excitation. A c-fos study. Eur J Pharmacol 1999, 378:17-22.

8. Irwin D, Milsom I, Hunskaar S, Reilly K, Kopp Z, Herschorn S, Coyne K, Kelleher C, Hampel C, Artibani W, Abrams P: Population-based survey of urinary incontinence, overactive bladder, and other lower urinary tract symptoms in five countries: results of the EPIC study. Eur Urol 2006, 50:1306-1315.

9. Herbison P, Hay-Smith J, Ellis G, Moore K: Efectiveness of anticholinergic drugs compared with placebo in the treatment of overactive bladder: systematic review. BMJ 2003, 326:84I-844.

10. Yoshimura N, Chancellor MB: Current and future pharmacological treatment for overactive bladder. I Urol 2002 168:1897-1913.

II. Avelino A, Cruz F: TRPVI (vanilloid receptor) in the urinary tract: expression, function and clinical applications. Naunyn Schmiedeberg's Arch Pharmacol 2006, 373(4):287-299.

12. Cruz F, Guimarães M, Silva C, Reis M: Supression of bladder hyperrelexia by intravesical resiniferatoxin. Lancet 1997 , 350(9078):640-641.

13. Lazzeri M, Beneforti P, Turini D: Urodynamic effects of intravesical resiniferatoxin in humans: preliminary results in stable and unstable detrusor. I Urol 1997, 158:2093-2096.

14. Silva C, Ribeiro MJ, Cruz F: The effect of intravesical resiniferatoxin in patients with idiopathic detrusor instability suggests that involuntary detrusor contractions are triggered by $\mathrm{C}$ fiber input. J Urol 2002, 168:575-579.

15. Brady CM, Apostolidis A, Yiangou Y, Baecker PA, Ford AP, Freeman $A$, Jacques TS, Fowler C], Anand P: P2X3-immunoreactive nerve fibres in neurogenic detrusor overactivity and the effect of intravesical resiniferatoxin. Eur Urol 2004, 46:247-253.

16. Silva C, Silva J, Ribeiro MJ, Avelino A, Cruz F: Urodynamic effect of intravesical resiniferatoxin in patients with neurogenic detrusor overactivity of spinal origin: results of a double-blind randomized placebo-controlled trial. Eur Urol 2005, 48:650-655.

17. Giannantoni A, Di Stasi SM, Stephen RL, Bini V, Costantini E, Porena $M$ : Intravesical resiniferatoxin versus botulinum-A toxin injections for neurogenic detrusor overactivity: a prospective randomized study. J Urol 2004, I72:240-243.

18. Kuo HC, Liu HT, Yang WC: Therapeutic effect of multiple resiniferatoxin intravesical instillations in patients with refractory detrusor overactivity: a randomized, double-blind, placebo controlled study. J Urol 2006, | 76:64|-645.

19. Apostolidis A, Gonzales GE, Fowler CJ: Effect of intravesical resiniferatoxin (RTX) on lower urinary tract symptoms, urodynamic parameters, and quality of life of patients with urodynamic increased bladder sensation. Eur Urol 2006, 50:1299-1305.

20. Silva C, Silva J, Castro H, Reis F, Dinis P, Avelino A, Cruz F: The effect of bladder sensory input modulation on urgency: data from a placebo controlled trial with intravesical resiniferatoxin [abstract]. Eur Urol 2006, 5(suppl 2):222.

21. Ghei M, Malone-Lee J: Using the circumstances of symptoms experience to assess the severity of urgency in the overactive bladder. J Urol 2005, 174:972-976.

22. Nixon A, Colman S, Sabounjian L, Sandage B, Schwiderski UE, Staskin $D R$, Zinner N: A validated patient reported measure of urinary urgency severity in overactive bladder for use in clinical trials. J Urol 2005, 174:604-607.

23. Cardozo L, Coyne KS, Versi E: Validation of the Urgency Perception Scale. BJU Int 2005, 95:591-596.

24. Brubaker L, Chapple C, Coyne KS, Kopp Z: Patient-reported outcomes in overactive bladder: importance for determining clinical effectiveness of treatment. Urology 2006, 68(2 suppl):3-8.

25. Szallasi A Blumberg PM. Vanilloid receptors: new insights enhance potential as therapeutic target. Pain 1996, 68:195-208.

26. Caterina MJ, Schumacher MA, Tominaga M, Rosen TA, Levine JD, Julius $D$ : The capsaicin receptor: a heat-activated ion channel in the pain pathway. Nature 1997, 389:816-824.

27. Liu L, Mansfield KJ, Kristiana I, Vaux KJ, Millard RJ, Burcher E: The molecular basis of urgency: regional difference of vanilloid receptor expression in the human urinary bladder. Neurourol Urodyn 2007, 26(3):433-438. doi:10.1002.nau.20326

28. Andersson KE: Treatment-resistant detrusor overactivity underlying pharmacologyand potential mechanisms. Int J Clin Pract 2006, 60(suppl I 5I):8-16.

29. Charrua A, Avelino A, Nagy I, Cruz F: Functional properties of TRPVI expressed in human urothelial cells [abstract]. Neurourol Urodyn 2006, 25:558.

30. Lowe EM, Anand P, Terenghi G, Williams-Chestnut RE Sinicropi DV, Osborne JL: Increased nerve growth factor in the urinary bladder of women with idiopathic sensory urgency and interstitial cystitis. Br J Urol 1997, 79:572-577.

31. Chuang YC, Fraser MO, Yu Y, Chancellor MB, de Groat WC Yoshimura $N$ : The role of bladder afferent pathways in bladder hyperactivity induced by the intravesical administration of nerve growth factor. I Urol 200I, 165:975-979.

32. Kim JC, Park EY, Seo SI, Park YH, Hwang T-K: Nerve growth factor and prostaglandins in the urine of female patients with overactive bladder. J Urol 2006, 175:1773-1776.

33. Birder LA, Nakamura Y, Kiss S, Nealen ML, Barrick S, Kanai Al, Wang E, Ruiz G, de Groat WC, Apodaca G, Watkins S, Caterina MJ: Altered Urinary bladder function in mice lacking the vanilloid receptor TRPVI. Nat Neurosci 2002, 5:856-860.

34. Cockayne DA, Hamilton SG, Zhu QM, Dunn PM, Zhong Y, Novakovic $S$, Malmberg AB, Cain G, Berson A, Kassotakis L, Hedley L, Lachnit WG, Burnstock G, McMahon SB, Ford APDW: Urinary bladder hyporreflexia and reduced pain-related behaviour in P2X3. deficient mice, Nature 2000, 407:1011-1015.

35. Trevisani M, Smart D, Gunthorpe MJ, Tognetto M, Barbieri M, Campi B, Amadesi S, Gray J, Jerman JC, Brough SJ, Owen D, Smith GD, Randall AD, Harrison S, Bianchi A, Davis JB, Geppetti P: Ethanol elicits and potentiates nociceptor responses via the vanilloid receptor- 1 . Nat Neurosci 2002, 5:546-55I.

36. van Leeuwen JHS, Castro R, Busse M, Bemelmans B: The placebo effect in the pharmacologic treatment of patients with lower urinary tract symptoms. Eur Urol 2006, 50:440-453.

\section{Pre-publication history}

The pre-publication history for this paper can be accessed here:

http://www.biomedcentral.com/1471-2490/7/9/prepub 